\title{
A Case Report of Sedation Strategy for a Patient With Coronavirus Disease 2019 Supported by Extracorporeal Membrane Oxygenation After Cesarean Section
}

\author{
Xiaozu Liao, MD, Zhou Cheng, MD, Junlin Wen, MD, Binfei Li, MD \\ Department of Anesthesiology, Zhongshan City People's Hospital, Zhongshan, China
}

\section{ABSTRACT}

Pneumonia caused by coronavirus disease 2019 (COVID$19)$ is a highly contagious disease. Unfortunately, research on extracorporeal membrane oxygenation (ECMO) assisted treatments for patients with COVID-19 infection is limited. In this case study, a patient who was in late pregnancy $(35+2$ weeks of pregnancy) and suffering from severe COVID-19 was extremely irritable during ECMO-assisted treatment after she underwent a cesarean section. Her Richmond Agitation Sedation Scale (RASS) score reached +3. Nevertheless, the patient successfully was treated with a continuous single/ combined application of propofol, midazolam, dexmedetomidine, hibernation mixture, and other drugs for several days (maintaining RASS -2 to -4 ) and provided with anti-infection, mechanical ventilation, nutritional support, fluid balance under hemodynamic monitoring, liver support, and other organ function support treatments. ECMO-assisted sedation strategy for patients was introduced and discussed in this case to provide a certain reference for the clinical diagnosis and treatment of such patients.

\section{INTRODUCTION}

ECMO-assisted treatment for patients who are in late pregnancy and suffering from severe COVID-19 is clinically rare, and current ECMO-assisted sedation practice for these patients lacks evidence-based guidelines [Shekar 2019; Lal 2019]. Reasonable sedation practice is closely related to the reduction of hospitalization time, mechanical ventilation time, hospitalization cost, mortality rate, and hospital infection rate of critically ill patients [Jackson 2010]. However, excessive sedation can cause adverse consequences, such as extended ventilator support time, increased hospitalization, and increased discharge mortality [DeBacker 2018; Shehabi 2012; Balzer 2015]. Some unique challenges are encountered in selecting a sedative during the ECMO-assisted treatment of patients infected with COVID-19. The sedation measures, during ECMO support for this case, were reported.

Received November 8, 2020; received in revised form November 15, 2020; accepted November 16, 2020.

Correspondence: Binfei Li, MD, Department of Anesthesiology, Zhongshan City People's Hospital, East Sunwen Road, Zhongshan City, Guangdong Province, China 528403; (86)13450921219 (e-mail: $286025919 @ q q . c o m$ ).

\section{CASE REPORT}

A patient, who was pregnant for $35+2$ weeks, was admitted to the hospital on February 1, 2020. She presented with a sore throat for four days and was running a fever with dyspnea for half a day. She also had a dry cough, nasal congestion, runny nose, chills, palpitations, and shortness of breath after she returned to Guangdong from Hubei. The symptoms were not significantly relieved after she received high-flow oxygen inhalation. Physical examination showed the following: respiratory rate of 39 breaths/min, body temperature of $39.5^{\circ} \mathrm{C}$, and oxygen saturation of $78 \%$. A ventilator immediately was applied through endotracheal intubation to assist ventilation, and emergency cesarean section, hemofiltration, anti-infection, booster, and other symptomatic treatments were performed in a bedside manner. An emergency chest CT revealed infection in the lower left lung, and the results
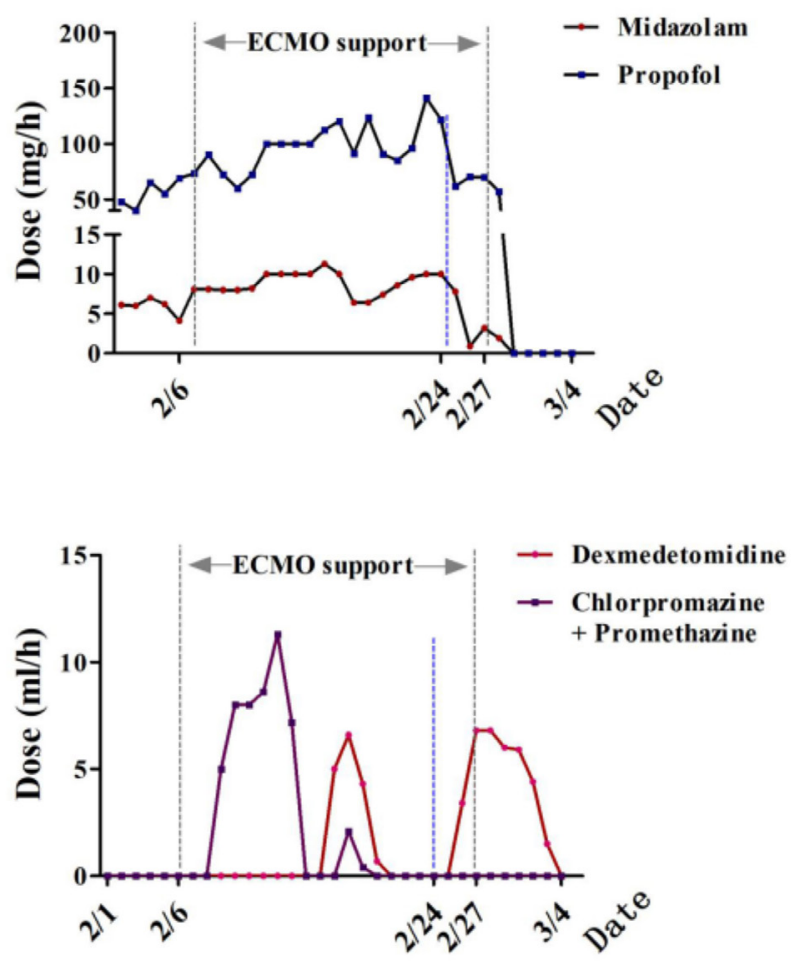

Drug use at different times. 
from the Municipal Disease Control Center showed that the oropharyngeal swab subjected to nucleic acid screening was positive for novel coronavirus 2019. She was then transferred to a designated hospital for further treatment.

Medical examination upon admission showed the following: body temperature of $36.3^{\circ} \mathrm{C}$; pulse, 150 times/min; breathing, 25 times/min; and blood pressure, $122 / 79 \mathrm{mmHg}$ (maintained by norepinephrine $2.0 \mathrm{ug} / \mathrm{kg} / \mathrm{min}$ ). She was under anesthesia in the hospital. The breath sounds in both lungs were thick, and moist rales could be heard. The heart rate was 150 beats/min, the rhythm was uniform, and no murmur was heard in the auscultation area of each valve. The aided examination revealed the following: $6.8 \times 10^{9} / \mathrm{L} \mathrm{WBC}$, 0.13 LYMPHR, 0.832 MEUTR, $110 \mathrm{~g} / \mathrm{L}$ HGB, 3.48 $\times 10^{12} / \mathrm{L}$ $\mathrm{RBC}$, and $160 \times 10^{9} / \mathrm{L}$ PLT. Preliminary diagnosis indicated the following: 1) novel coronavirus pneumonia (critical and severe); 2) septic shock; 3) multiple organ dysfunction syndrome (heart, lung, liver, kidney); and 4) late pregnancy $(35+2$ weeks of pregnancy) and after cesarean section.

The patient initially was treated with anti-infection, mechanical ventilation, nutritional support, fluid balance under hemodynamic monitoring. On February 6, 2020, she was further treated with VV ECMO for support as the oxygenation index $\left(\mathrm{PO}_{2} / \mathrm{FiO}_{2}\right)$ was $48 \mathrm{mmHg}$, $\mathrm{pH}$ was $7.15, \mathrm{PO}_{2}$ was $48 \mathrm{mmHg}$, and $\mathrm{PCO}_{2}$ was $68 \mathrm{mmHg}$ under high mechanical ventilation (tidal volume: $450 \mathrm{ml}$; respiratory frequency: $14 \mathrm{bpm}$; positive end expiratory pressure: $15 \mathrm{~cm} \cdot \mathrm{H}_{2} \mathrm{O}$; inspiratory peak pressure: $35 \mathrm{~cm} \cdot \mathrm{H}_{2} \mathrm{O}$; inhaled oxygen concentration: $100 \%)$. Originally, she was given lung-protective ventilation, and target tidal volume was $6 \mathrm{~mL} / \mathrm{kg}$ of predicted body weight and plateau pressure was $\leq 30 \mathrm{~cm} \mathrm{H} 2 \mathrm{O}$, but oxygen partial pressure $(\mathrm{PaO} 2)$ was $<50 \mathrm{mmHg}$. Deep sedation was induced with prone positioning, but the ratio of partial pressure to inspired $\mathrm{O}_{2}\left(\mathrm{PaO}_{2} / \mathrm{FiO}_{2}\right)$ was $48 \mathrm{mmHg}$ under high ventilator parameters.

The respiratory cycle also was not stable on the 6th day of hospital admission. The patient was abnormally agitated during ECMO-assisted therapy. The RASS score even reached +3 . The patient continuously was infused with midazolam, propofol, dexmedetomidine, and hibernation mixture for several days to maintain the RASS score at -2 to -4 (Figure). Tracheotomy was performed on February 24 to promote sputum excretion and reduce infection, and the machine successfully was withdrawn on February 27 . The patient finally recovered.

\section{DISCUSSION}

In this case, after the woman with COVID-19 was treated with ECMO, the average dosage of propofol increased from $52 \mathrm{mg} / \mathrm{h}$ to $93 \mathrm{mg} / \mathrm{h}$ and the average dosage of midazolam increased from $6.3 \mathrm{mg} / \mathrm{h}$ to $8.2 \mathrm{mg} / \mathrm{h}$ to maintain the previous sedation levels (RASS -2 to -4 ). The patient should intermittently be supplemented with dexmedetomidine and hibernation mixture for maintenance because of the changes in the pharmacokinetics of sedative drugs. Changes in drug pharmacokinetics caused by ECMO-assisted treatment include modifications in drug distribution and drug clearance that increase with increased circulation [DeGrado 2017]. In the present case, the blood and the drug concentration were further diluted because of the progressive increase in the volume of patients in late pregnancy. In addition, plasma concentration and drug effect can be influenced by the degree of plasma protein binding, the size of a drug molecule, and the time of oxygenator application [Shekar 2015]. The low concentration of lipophilic drugs in circulating plasma may be due to the isolation of ECMO oxygenators and pipelines. As the lipophilic drug propofol used in this case can be isolated from extracorporeal circulation (i.e., tubing and oxygenator), drug levels in plasma are reduced, so higher doses are needed to achieve the same clinical effect as that of patients without ECMO [Lal 2019; Hammaren 1999]. Patients on VV ECMO also seem to require higher doses than those of patients on VA ECMO [Lal 2019; Shekar 2012]. However, studies have yet to determine whether the patient's excessive irritability could be related to the attack of novel coronavirus 2019 on the central nervous system. Novel coronavirus 2019 initially was detected in the cerebrospinal fluid of patients with COVID-19 at Beijing Ditan Hospital, Capital Medical University. This result suggested that novel coronavirus 2019 might attack the central nervous system. However, more supporting data are required for identifying specific clinical manifestations and pathophysiological changes.

After ECMO-assisted tracheotomy, the average dosage of midazolam for the patient in this case was reduced from $8.6 \mathrm{mg} / \mathrm{h}$ to $6.2 \mathrm{mg} / \mathrm{h}$, and the average dosage of propofol was decreased from $94 \mathrm{mg} / \mathrm{h}$ to $84 \mathrm{mg} / \mathrm{h}$. In this case, viscous jelly-like sputum continued to be produced in the large and small airways of the patient's lungs, and it must be excreted to recover lung ventilation. Early tracheotomy may help reduce the patient's need for sedation, induce sputum production, shorten ECMO maintenance time, and promote the patient's ability to eat, drink, and vocalize [Shekar 2019]. Some studies have performed tracheotomy on 616 patients undergoing VV ECMO because of respiratory failure. The amount of sedative drugs is decreased; spontaneous breathing function is increased; the mean airway pressure, positive end-expiratory pressure, ECMO blood flow, and gas flow are reduced; and tidal volume is increased [Fisser 2019]. Therefore, early tracheotomy assisted with ECMO for patients with COVID-19 might help reduce the application of sedative drugs and accelerate the recovery of lung function.

Further studies have shown that inhaled anesthetic drugs positively affect ECMO-assisted sedation for patients. German and Spanish sedation guidelines for critically ill patients recommend inhalation anesthetics (such as isoflurane) as an alternative to intravenous sedation [Baron 2015; Celis-Rodríguez 2013]. Isoflurane can achieve bronchiectasis and lung protection, which are beneficial to patients with ARDS and patients receiving ECMO treatment. Moreover, inhalation sedation is not related to hemodynamic instability [Meiser 2017]. Therefore, anesthetic drug inhalation showed potential for application in sedating patients infected by novel coronavirus 2019 during ECMO-assisted treatment. 
Balancing between optimal sedation levels, maximizing ECMO flow, and minimizing oxygen consumption in the case of pharmacokinetic changes during ECMO-assisted treatment may be difficult because of the lack of solid clinical pharmacokinetic data in guiding the medication of ECMOassisted patients [Shekar 2012]. The goal of sedation during ECMO, the application of EEG bispectral index monitoring, and timing of patients undergoing tracheotomy can serve as a basis for applying sedation practices to a certain extent. The pharmacokinetics of sedative drugs related to ECMO mostly come from in vitro. Therefore, further clinical research is urgently needed to guide the medication of such patients.

\section{REFERENCES}

Balzer F, Weiß B, Kumpf O, et al. 2015. Early deep sedation is associated with decreased in-hospital and two-year follow-up survival. Critical Care. 19(1): 197.

Baron R, Binder A, Biniek R, et al. 2015. Evidence and consensus based guideline for the management of delirium, analgesia, and sedation in intensive care medicine. Revision 2015 (DAS-Guideline 2015)-short version. GMS German Medical Science. 13.

Celis-Rodríguez E, Birchenall C, de la Cal M, et al. 2013. Federación Panamericana e Ibérica de Sociedades de Medicina Crítica y Terapia Intensiva. Clinical practice guidelines for evidence-based management of sedoanalgesia in critically ill adult patients. Med Intensiva. 37(8): 519-574.

deBacker J, Tamberg E, Munshi L, et al. 2018. Sedation Practice in Extracorporeal Membrane Oxygenation-Treated Patients with Acute Respiratory Distress Syndrome: A Retrospective Study. Asaio Journal. 64(4): 544-551.

DeGrado JR, Hohlfelder B, Ritchie BM, et al. 2017. Evaluation of sedatives, analgesics, and neuromuscular blocking agents in adults receiving extracorporeal membrane oxygenation. Journal of critical care. 37(1-6).
Fisser C, Lüdtke P, Lubnow M, et al. 2019. Effect of tracheotomy on sedation, ventilation and ECMO adjustments in patients with acute respiratory failure on venovenous ECMO: a 10-year analysis [M]. Eur Respiratory Soc.

Hammaren E, Rosenberg P, Hynynen M. 1999. Coating of extracorporeal circuit with heparin does not prevent sequestration of propofol in vitro. British journal of anaesthesia. 82(1): 38-40.

Jackson DL, Proudfoot CW, Cann KF, et al. 2010. A systematic review of the impact of sedation practice in the ICU on resource use, costs and patient safety. Critical Care, 14(2): R59.

Lal A, Nabzdyk C, Ramakrishna H, et al. 2019. Consider Heightened Awareness of Propofol Infusion Syndrome after Extracorporeal Membrane Oxygenation (ECMO) Decannulation. Journal of Cardiothoracic and Vascular Anesthesia.

Meiser A, Bomberg H, Lepper P M, et al. 2017. Inhaled sedation in patients with acute respiratory distress syndrome undergoing extracorporeal membrane oxygenation. Anesthesia \& Analgesia. 125(4): 1235-1239.

Shehabi Y, Bellomo R, Reade M, et al. 2012. Sedation Practice in Intensive Care Evaluation (SPICE) Study Investigators; ANZICS Clinical Trials Group. Early intensive care sedation predicts long-term mortality in ventilated critically ill patients. Am J Respir Crit Care Med. 186(8): 724-731.

Shekar K, Grewal J, Sutt A L, et al. 2019. Individualizing sedation in acute respiratory distress syndrome patients on extracorporeal membrane oxygenation. Asaio Journal. 65(4): e44-e45.

Shekar K, Roberts J, Ghassabian S, et al. 2012. Sedation during extracorporeal membrane oxygenation-why more is less. Anaesthesia and intensive care. 40(6): 1067-1069.

Shekar K, Roberts JA, Mcdonald CI, et al. 2015. Protein-bound drugs are prone to sequestration in the extracorporeal membrane oxygenation circuit: results from an ex vivo study. Critical Care. 19(1): 164.

Shekar K, Roberts JA, Mullany DV, et al. 2012. Increased sedation requirements in patients receiving extracorporeal membrane oxygenation for respiratory and cardiorespiratory failure. Anaesthesia and intensive care. 40(4): 648-655. 